\title{
Changing Dark Coal into Illuminating High-Tech \\ - Ways out of an Economic Crisis in Dortmund, Germany
}

\author{
Eberhard Becker ${ }^{1 *}$ and Simone Herrmann ${ }^{2}$ \\ Dept. of Mathematics, TU Dortmund University, ${ }_{1}$ TechnologieZentrum Dortmund, ${ }^{2}$ Germany
}

\begin{abstract}
Federal investments into the future of a region" - pushing economy in the right direction or throwing tax money into a black hole? Hot-headed contentions keep circulating within politics and economy discussing the effect of technology centers and their sustainability within a region. Start-up support and technological infrastructure with the auxiliary service of well developed sector-oriented clusters as a fertile soil for successful networks are an undeniable advantage of well organised technology centers. Sceptic contemporaries still hold against that in order to implement such a center millions of federal funds for infrastructure and operation are invested. What output of this tax money is verifiable in the long run?

The case of Dortmund provides substantial food for this necessary and relevant discussion. Now, after 27 years of history of the TechnologieZentrumDortmund, TZDO for short, a positive balance can be drawn. This is not just a matter of personal belief and stance. Fortunately, a recent study on the economic effects of the TZDO on the whole region was performed by the Center of Applied Economy Research Münster, Germany (Gundel and Luttmann 2008). The result is clear and measurable: the TZDO has shown to be of great impact on the positive development of a whole region.

This paper presents an account of the approach of the TechnologieZentrumDortmund and its current strategy and mode of operation to reach an utmost of effectiveness of personal and pecuniary input in establishing economic success for the region of Dortmund. An immense change of minds, employment opportunities and a massive structural change of the whole region were some of the ambitious aims that had to be reached and that are achieved to a large extent.
\end{abstract}

\section{INTRODUCTION}

The city of Dortmund is located in the federal state of North Rhine Westphalia (NRW) in the western part of Germany. This state is Germany's largest with respect to population (17 million inhabitants). The metropolitan area of the Ruhr, a region of around 4,500 km², 53 communes and a population of 5.2 million is situated in this state. Located at the eastern edge of this area, Dortmund is one of these

*Correspondence to : Prof. Eberhard Becker

Prof. em., Dept. of Mathematics, TU Dortmund University

E-mail : eberhard.becker@tu-dortmund.de

World Technopolis Review

Copyright $(\mathcal{O W}$ World Technopolis Association

CC This is an open-access article distributed under the terms of the Creative Commons Attribution Non-Commercial License(http://creativecommons.org/licenses/by-nc/3.0) which permits unrestricted noncommercial use, distribution, and reproduction in any medium, provided the original work is properly cited communes - with about 600,000 inhabitants the seventhlargest city in Germany and a regional metropolis.

For a period of more than 100 years the economy of Dortmund was based on coal mining and the production of steel. In addition, Dortmund was famous for its beer industry. One may say that Dortmund and its region essentially contributed to Germany's industrial productivity and wealth for decades. However, starting in the late seventies of the last century the decline of these industrial sectors began, as to be seen in many others places all over the world, and affected the fortune of Dortmund severely. In particular, in the year 1997 the two biggest steel producing companies in Germany of "Thyssen" and "Krupp Hoesch" decided to merge and to close the steel production in the City of Dortmund and to concentrate it in the City of Duisburg, located at the other edge of the Ruhr area, about $100 \mathrm{~km}$ apart. With the withdrawal of ThyssenKrupp steel produc- 


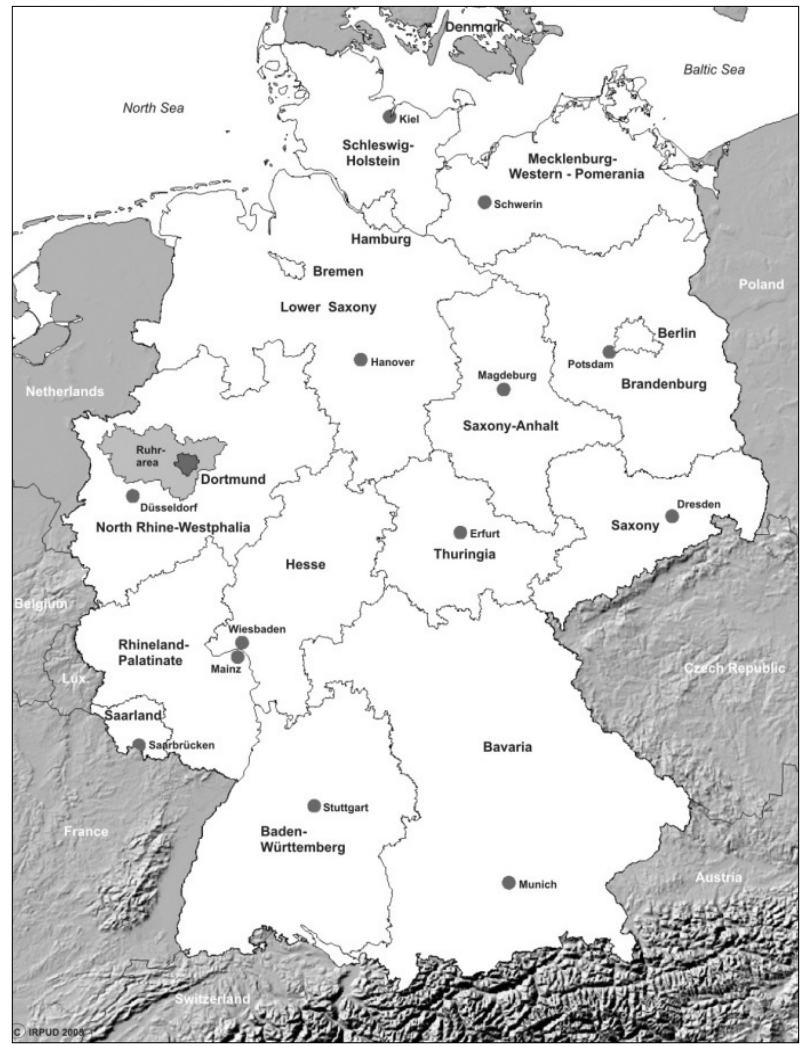

Fig. 1. Geographic Location of Dortmund in Germany Source: Institute of Spatial Planning, TU Dortmund University

tion in Dortmund came to a definite end.

To date, the successful period of the coal, steel and beer industries is history. In a short while, Dortmund had suffered the loss of 80,000 jobs. The community and the economic sector were facing the nearly hopeless task to create a big number of jobs in a short period, i.e. to design promising counteractions and a plan for the future.

There are two main activities, broadly scoped, which are of interest for this paper:

- the development of the TechnologieZentrumDortmund (TZDO-started in 1985) and the TechnologiePark Dortmund (TPDO-started in 1988)

- the development and implementation of the city development model dortmund-project (started in 2000) with its cluster-initiatives.

We will concentrate on the first issue whereas the second one will only be alluded to.

To recall the situation in Dortmund as of 30 years ago it is fair to state that peoples 'income was then either earned in coal mines, the steel industry, beer breweries or some highly respected jobs in the service sector. This has changed dramatically. To date, one out of 5 employment opportunities in Dortmund is provided by science, research and high-tech companies. E.g., starting up an own company no longer is an alien concept. Scientific and technological progress achieved in universities and institutes are transferred into marketable products within a minimum of time due to excellent working synergies among science and economy.

From a more general perspective, what has been developed in Dortmund and its surrounding region is a convincing example of Regional Innovation Policy. In (Becker, Burger and Hülsmann 2012) the recent economic development of Dortmund is studied from this point of view. Suitably adjusted, a few parts of that paper are duplicated here.

\section{ECONOMIC CRISIS AND WAYS OF RECOVERY}

\subsection{The Dortmund Consensus and the Creation of TechnologieZentrumDortmund and - TechnologieParkDortmund}

The process of declining traditional industries seriously affected the economic basis of the whole Ruhr area already before 1980. Its aggravating effect was clearly visible in the 80 's of the last century and resulted in a loss of 80,000 jobs at the end. A new basis for economic development was urgently needed.

It was then when various stakeholders in the city of Dortmund amazingly fast reached a consensus regarding the analysis of the situation and the concepts suitable for the future recovery of the presently decaying traditional industry. This consensus has been referred to as the "Dortmund Consensus" ever since and formed the basis, shared by all, for a remarkable transition from old to new economic structures. While searching for innovative ways to promote the restructuring of the region, a Dortmund initiative led to the establishment of a TechnologieZentrum and a TechnologiePark. The founding fathers, so to say, were

- Dortmund's institutions of higher education,

- The City

- The local Chambers of Commerce.

- Dortmund's financial institution 


\section{Best Practice of Science / Technology Parks}

The opportunity was grasped quickly. In 1985, 16 months after the preliminary negotiations, the first buildings were completed. Here Dortmund was among the pioneers in Germany, second only to Aix-la-Chapelle and Berlin.

The idea itself and the prompt implementation of the project were attributable to the advantages that the institutions of higher education and the city undoubtedly possessed, as well as the willingness of all partners involved. E.g., the TU Dortmund University had deliberately developed strength in the fields of engineering, computer science and the natural sciences, and therefore the potential for innovation was high. In addition, the University is situated on a large greenfield site that offered enough space for an industrial periphery.

The outline and structure of TechnologieZentrumDortmund became a model for German innovation centers. It has concentrated both on technological development and spin-off companies. Doing so, it is supporting the development and the application of technological products as well as helping and encouraging young entrepreneurs wishing to set up a business.
Since its early days the TechnologieZentrumDortmund has evolved into one of the most successful and largest centers in Germany. In 10 building complexes with floor space of $120,000 \mathrm{~m}^{2}$ it accommodates about 190 companies with more than 1,500 employees.

The adjacent area of 40 ha next to the joint campus of the TU Dortmund University and the TZDO for the TechnologieParkDortmund was planned already in the zoning map in 1985 when the TZDO was founded. First construction activities started here in 1988 after the second construction section of the TZDO was completed in 1987. The park offers young enterprises which have hatched out of the incubator TechnologZentrumDortmund space for the construction of own premises. It is likewise an excellent location for enterprises which seek contact to scientific institutions but have no need for the kind of support provided in the TechnologieZentrumDortmund. The TechnologieParkDortmund has grown fast and accommodates today more than 250 companies with over 8,000 employees. TZDO and TPDO together have created more than 13,000 employment oppor-

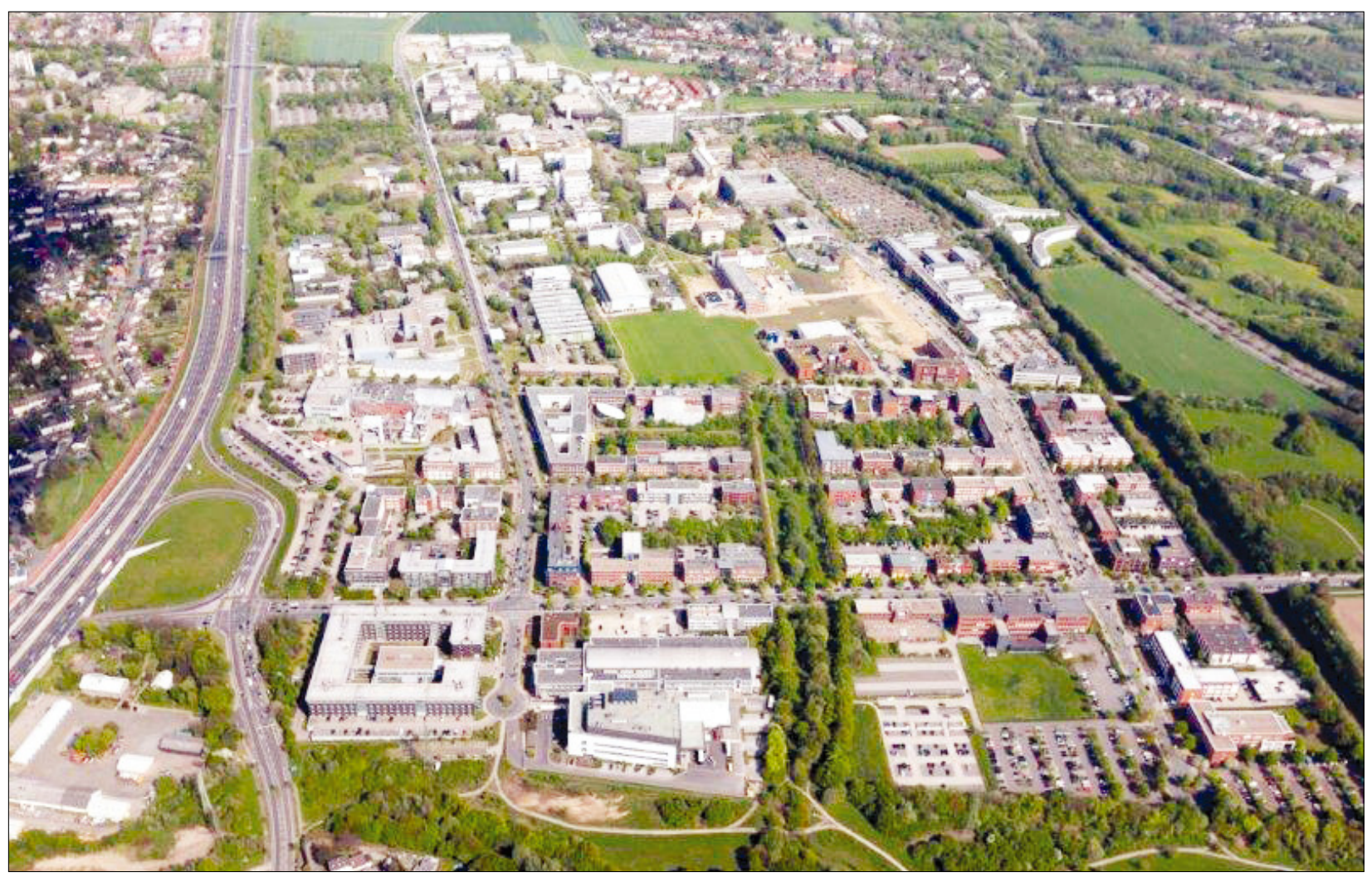

Fig. 2. Dortmund Campus with TZDO and Park

Source: TechnologieZentrumDortmund 
tunities, direct or indirect, where about 9,500 employees are residents of Dortmund. TZDO and Park are focusing on areas and companies of modern high technology. This requires close contact to research entities which are available in Dortmund such as, e.g.

- TU Dortmund University, the University of Applied Science

- Max Planck Institute for Molecular Physiology

- Two Fraunhofer Institutes for Logistics and Information Technologies respectively

- Two Leibniz Institutes for Analytical Science and, respectively, Working Environments and Human Factors

Various financing schemes have been established and are still being used. Venture capital and seed funds were made available by local institutions. In addition, a combination of investments from the City of Dortmund, the regional State of North-Rhine-Westfalia and European Structure Funds is being applied to secure a financial basis.

\subsection{The Dortmund-Project}

As said in the introduction the Dortmund-project is not in the focus of this paper. However, the dortmund-project is to be seen as a general and broad master plan for restructuring and fostering Dortmund's economy. As such, it has strong impact on the development of TZDO and the TechnologieParkDortmund.

To explain the establishment of the initiative dortmundproject one has to go back to the year 1997 and the decision of the two biggest steel producing companies in Germany of "Thyssen" and "Krupp Hoesch" to merge and to close the steel production in the City of Dortmund. Within a Memorandum of Understanding both companies agreed upon certain activities to substitute and replace the jobs lost, including the establishment of an automotive supply factory in Dortmund. After some counselling, the ThyssenKrupp AG engaged the consulting company McKinsey \& Company to development a ten year strategy for the City of Dortmund to halve the unemployment rate.

In June 2000, as a first step of implementation, the Dortmund City Council voted to establish the dortmundproject under the direct supervision of the Lord Mayor and reserved budgets of approximately $€ 5$ million per annum up to the year 2010. From the very beginning the dortmundproject was supported by ThyssenKrupp AG and the
Economic and Employment Promotion Office Dortmund which is part of the City's administration.

The overall strategy was described in six goals:

- To set up new anchor industries in Dortmund

- To strengthen companies resident in Dortmund

- To expand training programmes, skills upgrading schemes and R\&D of an international standard

- To turn the City of Dortmund into a modern business city with a high quality of life and unrivalled leisure amenities

- To expedite planning and approvals procedures: onestop shopping for start-up and/or relocating companies

- To substantially boost the level of employment

The dortmund-project, to say the least, has created an atmosphere where economic recovery and entrepreneurial spirit can prosper. It has helped the city to cope with huge economic challenges although not all goals have been reached fully by now, unemployment is still high e.g. But without the dortmund-project and the many activities built in it is hard to imagine how Dortmund could have reached the present economic level envied by other cities in the Ruhr area.

\section{FEATURES OF TZDO AND TPDO}

After outlining of the structure, scope and the principal modes of operation we are drawing attention to selected topics which, as typical samples, can outline the strategy followed by shareholders and management of the TZDO.

\subsection{Structure and Scope}

The TZDO is a private limited liability company with the following shareholders:

- the two universities in Dortmund

- the chambers of commerce and handicrafts respectively

- the City of Dortmund

- various financial institutions.

It is run by a management board where intimate connection with the City is maintained.

The TechnologieZentrumDortmund offers companies a complete service package. This offer ranges from communication devices, including reception and telephone services, 
participation at trade fairs and events, national and international contacts and cooperative aid and is completed by extensive consulting services through qualified specialists.

The TZDO is designed as a development center and a laboratory for testing prototypes and preproduction batches in selected technological fields which are based upon the technologies pooled from Dortmund's scientific and economic potential.

At present the TZDO's policy focus on the following technological areas

- Microsystems- and Nanotechnology

- Software/Telecommunication/Multimedia

- Electronics/Electromagnetic Compatibility/Electro mobility

- Quality Assurance

- Logistics/Material Flow/Packaging

- Environmental Technology

- Production Technologies/Automation

- Biomedicine/Proteomics/Bio-IT

- Photonics and Molecular Electronics (drafted)

Whenever the provision of scientific and technological infrastructure amounts to very high expenses and a costeffective usage is imperative TZDO follows the principle to build so called Competence Centers where tenant companies share common equipment and infrastructure. Along this line, amongst others, the following competence centers have been established:

- BioMedizinZentrumDortmund (Bio medicine center)

- MST.factory dortmund

- eport Dortmund (Center for e-logistics)

- Zentrum für Produktionstechnologie (Center for Production Technology)

Even though tenants in the TechnologieZentrumDortmund are enjoying the provision of high-tech infrastructure and general assistance, they pay suitable leases according to location and service level. In addition, proximity to various scientific institutions is an attractive feature. So far, the whole package is very convincing. An average rental quote of $90 \%$ is reached continuously.

The administration of available property either for construction or rental objects in the TechnologieParkDortmund is mainly done by the economy support of the city. There growing companies could either build themselves or find an investor to build according to their needs and rent it from that company. Meanwhile the whole area is occupied and developed due to the formally agreed zoning map which had to fulfil the requirements of for instance not building higher than two floors and leaving a green gap of 12 meters after 24 meters of construction. A so called "white field" of approximately 8 ha is still available in the close neighbourhood. In order to retain a unique appearance of the whole park the TZDO operates the website of the TechnologieParkDortmund as well as its own.

As mentioned before, the complete system of financing is a sophisticated combination of income by rents effectuated as well as funding schemes provided by the City, the regional and federal state and the European Commission which are normally offered through competitive calls for proposals. A great deal of attention and work is paid in order to be successful in competing with other contenders.

\subsection{Support of SMEs}

\subsubsection{Attracting investment}

Companies are assisted to get in touch with credit institutes for financing their projects. In addition, the management is involved in attracting the interest of venture capital funds, e.g. the Seed Capital Funds or the HighTechGründerfonds (founders funds). There is a substantial list of companies which successfully attracted funding this way.

This enormous help even more speeds up the development of generating marketable products from the results of $\mathrm{R} \& \mathrm{D}$ of the universities and institutes in our close neighbourhood.

\subsubsection{Technology transfer}

The TZDO is instrumental in fostering technology transfer from the various scientific institutions, listed in section 2.1 , into the economic world. It is prepared to assume its role in the whole value chain from scientific results into market. Among various examples one case is outstanding: the Lead Discovery Center $\mathrm{GmbH}$, which is the result of intense cooperation between the Max-Planck Institute of Molecular Physiology in Dortmund, the universities in Dortmund and Bochum (a neighbouring City) and, first of all, a successful resident company in the BioMedizinZentrumDortmund, one of the Competence Centers of TZDO. More details can be found in the press release (MaxPlanck-Innovation 2008).

Another effort to strengthen the knowledge and technology transfer is the implementation of the "Leitbild 
Innovationskultur" (in English: "Overall Concept for a Culture of Innovation") which was initiated by the Economy Promotion Office of Dortmund and its various neighbouring cities, the Chambers of Commerce and Trade, the Chambers of Handycrafts, the Universities in Dortmund and the technology centers of a whole region around Dortmund. Starting in 2007, several activities have been launched to achieve a better understanding among business people and university members. Both sides have agreed in enhancing a mutual perception in order to lift the huge potential which is implied in a closer cooperation.

\subsubsection{Pre-incubation and incubation}

The TZDO, jointly with four other technology centers in the region of Dortmund and the University, succeeded in attracting federal funding for a pre-incubation project referred to as the Pre-incubator Center (PINC). This center offers support to university graduates wanting to set up a business. They receive support in all planning phases from the idea to the foundation itself. To do so, the technology centers involved are providing the complete scale of their infrastructure of service and advice. Assistance for working out a business plan, selecting the right promotion programme and mediate contacts with industry, financial institutes, research establishments, universities and polytechnics is another important facet of this project.

More advanced companies in the TZDO which are in the phase of incubation are periodically asked to review the center's performance and communicate to the management their degree of contentedness. This way information is gathered on how to improve the services, the catering to the needs of the tenants regarding infrastructure as well as topics and structure of information events. E.g., the project managers in the specific competence centers offer assistance in submitting tenders for calls of proposals on a national just as European basis.

\subsubsection{Internationalisation}

Two lines of internationalisation are pursued: housing international companies and, on the other hand, assisting tenants in their establishment of their own international contacts. In the sequel activities are sketched where both policies interact: giving companies access to the Asian markets, especially to South-Korea.

Within the framework of the joint initiative "dortmundproject" the City of Dortmund in 2003 launched a marketing tour to attract technology orientated companies to the location of Dortmund. Between 2003 and 2005 several roadshows took place, delegations were invited to visit Dortmund and the TechnologieZentrumDortmund including its innovative companies. In 2005 a first company from South-Korea decided to open its European branch in Dortmund. They were followed by other firms from SouthKorea. A year later, a Korean consulting company moved its office to the TechnologieZentrumDonortmund. In each case it was the advantages of the Dortmund-project network just as Dortmunds good reputation as a site of modern technology that made those companies chooses Dortmund as a promising location for their business. After the first steps several cooperation agreements with Korean partners were concluded such as governmental agencies, business associations and several technology parks. The City of Dortmund and the TechnologieZentrumDortmund in particular are willing and prepared to evolve into a leading hub for SouthKorean technology businesses in Germany and Europe.

\subsection{The BioMedizinZentrumDortmund}

This center, for short BMZ, in English, the "Bio Medical Center Dortmund," was built in three steps between 2002 and 2009 and 2012 with an investment of $€ 55$ million and provides a total area of $20,000 \mathrm{~m}^{2}$ with $12,000 \mathrm{~m}^{2}$ of equipped laboratories. Within just a few years an internationally considered Biotech-Cluster has been developed in Dortmund, focusing on biotechnology, medical engineering and bio-IT. Meanwhile modern R \& D facilities, emergent technology companies and pioneering joint projects shape the site, which are mainly located on the campus of the Technische Universität Dortmund and in the TechnologieParkDortmund. To date, BMZ houses 26 companies with more than 350 employees.

840 scientific associates working in internationally renowned institutes account for a prominent position of Dortmund as a site for biotechnology and biomedicine. Located in Dortmund itself is the Max-Planck-Institute for Molecular Physiology, the TU Dortmund University, the university of applied sciences and two Leibniz Institutes: the Institute for Analytical Science (ISAS) and the Research Center for Working Environment and Human Factors (IfADo) which provide their resources by means of personnel and scientific environment.

The Max-Planck-Institute for Molecular Physiology (MPI) is one of the leading German institutions in the field of funda- 


\section{Best Practice of Science / Technology Parks}

\section{Enlargement due to the tenants needs}

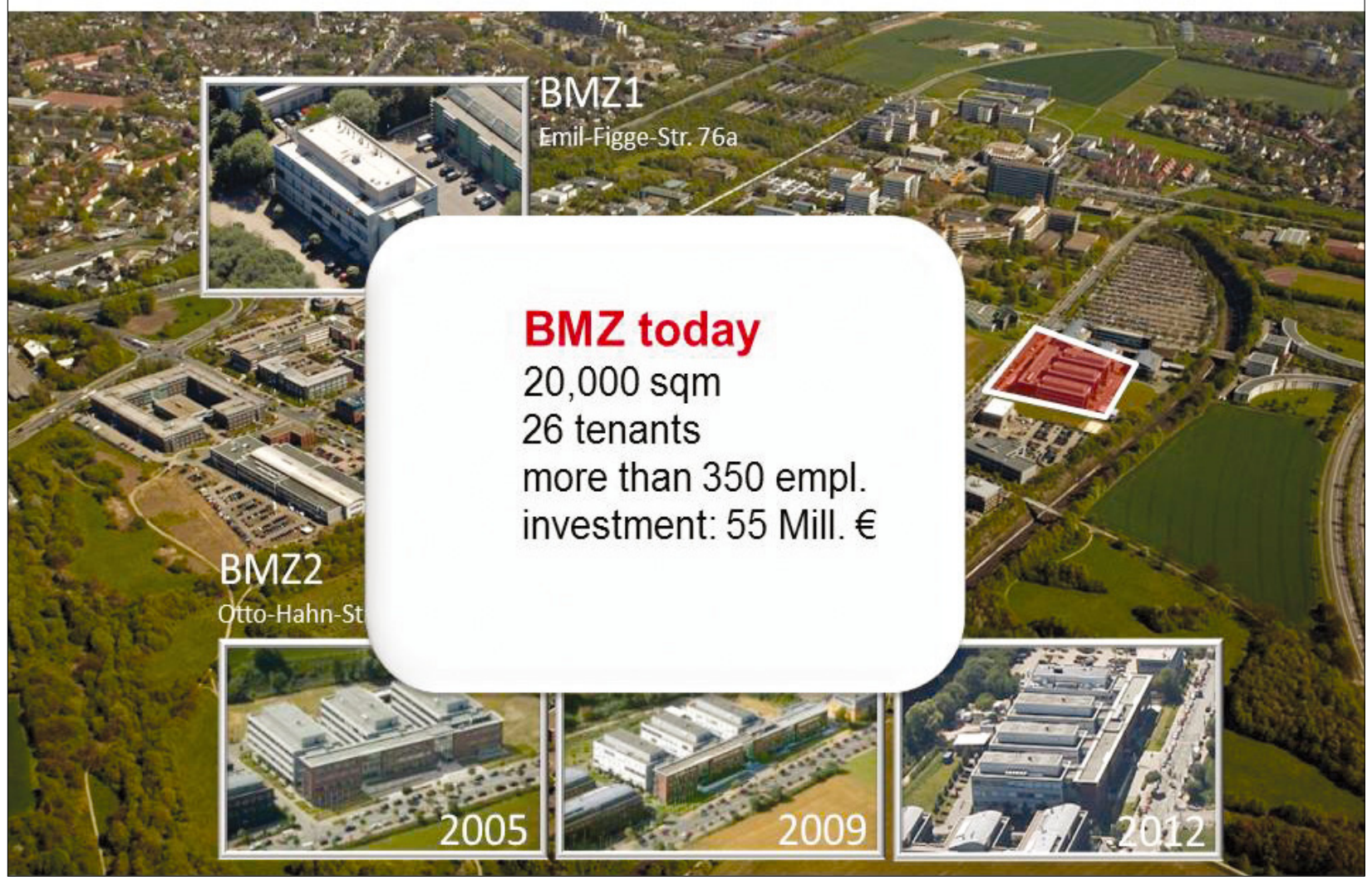

Fig. 3. Enlargement due to the tenants needs

mental research in biomedicine. The cooperation of international scientists coming from different disciplines lead to an interlocking of biology and chemistry. This way already numerous mechanisms could be discovered which are conductive to the emergence of tumours and neurological abnormal development.

The TU Dortmund University has achieved international reputation for offering application-oriented research and as a source for several projects in the field of biotechnology. More than 2,500 students are educated in biotechnologyaffine degree programs.

TZDO has developed a concept of incubating technology focused competence centers such as this center or cluster BMZ. Along this lines TZDO successfully conduct the concert of universities, R \& D institutions and technology based young companies. A very prominent example is given by the so called "Lebenswissenschaftliche Innovationsplattform," in English "Platform for Innovation in Life Science" that was founded in 2006 with overall investment of more than $€ 45$ million. Scientific partners from the universities in Bochum and Dortmund and the Max-Planck-Institute for Molecular Physiology and industrial partners came together under the guidance of TZDO to form a liaison in Life Science. Three sub centers were formed, on System Biology, Applied Chemical Genomics and on Applied Proteomics.

\subsection{Micro-, Nano- and Production Technology}

Since 2005 TZDO has built two further competence centers: the MST.factory dortmund for Micro- and Nano Technology and more recently a center for Production Technology. They were built on the brown field left behind after the demolition of the last steel mill in Dortmund. The photos below provide a clear image what is meant by the title of this paper. Visible are still the remains of the past of coal and steel but at the same time one can easily identify the modern buildings of the future. 

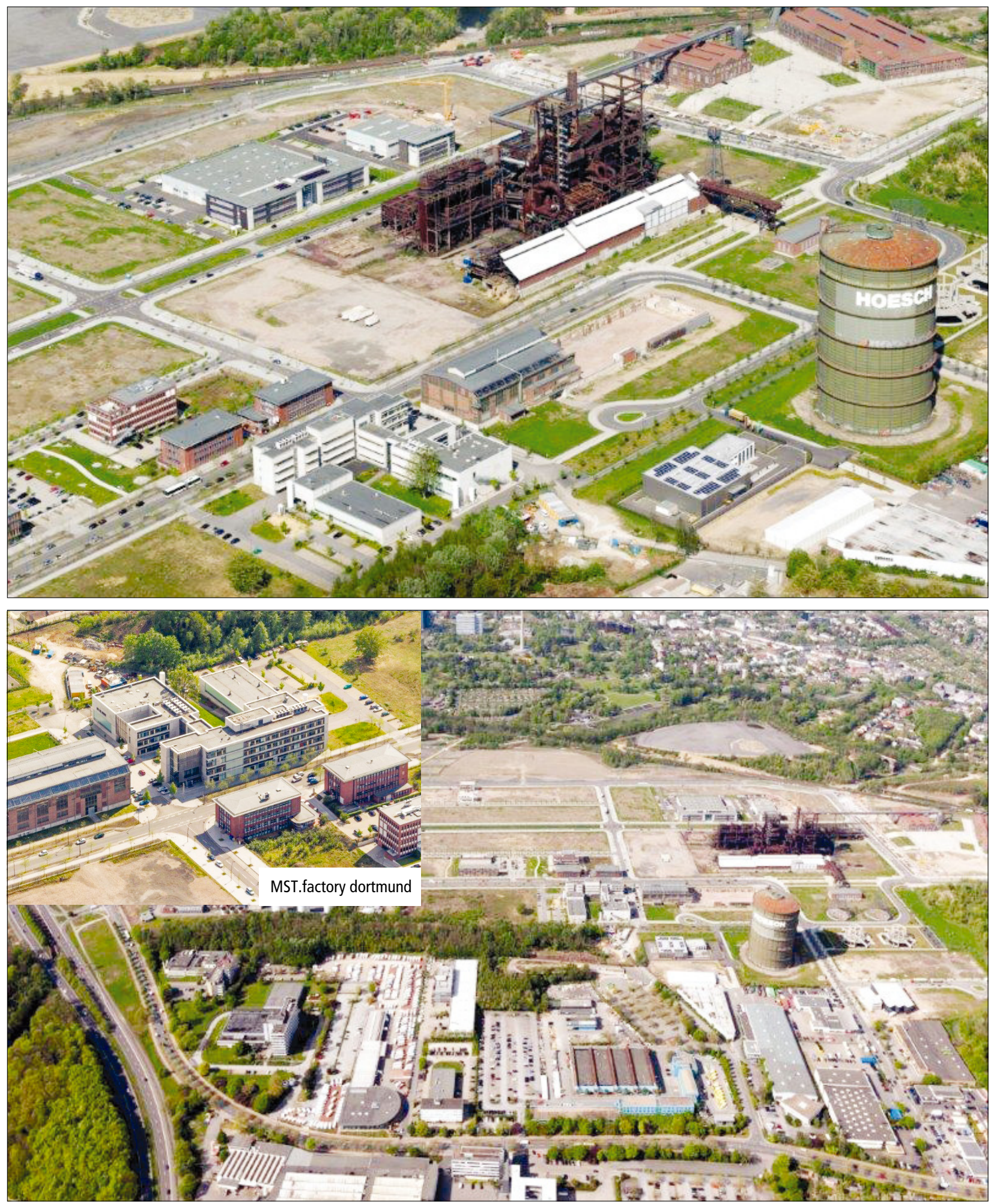

Fig. 4. Center for Production Technology and MST.factory

Source: TZDO 
To use these brown fields for establishing new industries is not by accident, it is rather part of a general master plan of restructuring the City of Dortmund, a town the face of which was heavily dominated by coal mines and steel mills for a long period of its history. For more details see www.phoenixdortmund.de.

The MST.factory is part of the more comprehensive microsystem-cluster of Dortmund that has evolved under the umbrella of the dortmund-project. As of 2012, there are more than 2,000 employees in about 40 enterprises. These companies show an unusual high percentage of employees with an academic background. In $1 / 3$ of those companies the share of academically trained personnel is $75 \%$ and higher. In fact, Dortmund and the region offer an ample supply of well trained employees. Within a circle of $100 \mathrm{~km}$ around Dortmund a considerable number of universities with more then 50,000 students in engineering and natural science are located.

The MST.factory itself was constructed in two steps, 2005 and 2007 with an investment of about $€ 50$ million. It offers about $10,000 \mathrm{~m}^{2}$ in total, modern facilities and equipment. Start-up companies as well as mature enterprises enjoy a highly professional infrastructure that enables them to transfer their ideas within a minimum of time from research, via prototypes into marketable products.

Dortmund's fostering of business related to micro- and nano-technology has received high recognition: the results were assessed extraordinary. IVAM (Kleink 2004) came to the conclusion that the location of Dortmund with its 40 MST companies and more than 2,300 employees constitute the cluster with the highest number of MST companies in Germany. The number of employees in the MST companies of Dortmund had an average annual growth of $15 \%$ throughout the last years. To provide a compact overview of the MST companies in Dortmund the website www.microtechdortmund.com was established. This also serves the regional partners for networking and easy communication.

In 2008 the Zentrum für Produktionstechnologie (Center for Production Technology) was ready for its first tenants after an investment of on $€ 25$ million of public investment. About $10,000 \mathrm{~m}^{2}$ space for 250 employees are provided. This center attracts companies in production and manufacturing technologies with special emphasis on linkage to other hightech branches available in the region of Dortmund, in particular at the interface between production and micro- and nano technology or automotive industries.

\section{ECONOMIC AND STRUCTURAL EFFECTS}

\author{
"Federal investments into the future of a region" - \\ pushing economy in the right direction or throwing tax \\ money into a black hole?
}

This question was raised at the very beginning of this paper. This section will present an answer based on a study of 2008 (Gundel and Luttmann 2008) that measures the impact on the economy as well as the tax revenues attributable to the TZDO and TPDO jointly taken into account. The effects were investigated in the context of the whole region around Dortmund, partly even nationwide. An impact on the economy arises in two ways: The quantitative analysis is concerned with gross value added, gross wages and salaries and the tax revenue whereas a more qualitative consideration deals with the capacity for innovation and the professional level of employees.

To facilitate terminology, TechnologieZentrumDortmund and TechnologieParkDortmund will jointly be referred to as TPDO, thus deviating from the convention we have applied so far. This in line with the study of Gundel and Luttman we refer to in this section. It is nearly impossible to separate TZDO and TPDO when economics effects are being studied. In addition, in view of Dortmund's economic policy center and park are intimately related to each other, they are interlocked. It wouldn't make any political sense to separate them in into individual entities.

To establish TPDO an amount of about $€ 200$ million of public funds has been spent since its foundation in 1985. This spending has to be balanced against the gross value added, fiscal revenue and other positive effects that were hoped for. To present the quantitative effects various concepts have to be introduced. What follows is a less refined version of the sophisticated scheme used in the study. For details of the methodology the study itself has to be resorted to. Yet, the basic message of the study can be conveyed as given below.

\section{Direct Effects}

Under this heading all economic activities on the compound of the TDPO are summarized. Companies which are located there are producing goods and selling services, and they pay wages and salaries to their employees.

\section{Indirect Effects}

These effects result from the fact that the companies 
inside the TPDO on their part demand industrial and investment goods from other manufacturers, service providers or financial institutions. These activities give rise to an increase in production, employment and income in companies of other locations as well.

\section{Induced Effects}

The induced effects result from revenues generated by employees of all firms referred to above. These expenses boost the consumer goods industries by means for production, employment and income.

\section{Gross value added}

To calculate this figure the gross value realized by the companies inside the TPDO is detected first. In the next step the gross value of the goods demanded from other companies is taken into account. The results in EUR are presented in the below listed chart.

\section{National or regional reference}

In order to be able to produce goods the firms inside to TPDO have to cooperate with enterprises outside this compound. It is a fact that the majority of those business partners live in the closer region of Dortmund. However, in a considerable number of cases they cannot be found nearby. In particular, very often this applies to TPDO tenants with a high tech profile. Employees do not necessarily reside in the city of Dortmund. The great majority is located in a certain regional neighbourhood of Dortmund, including Dortmund itself. One may assume that their consumption takes place in the vicinity of their residence.

Therefore in measuring the economic effects a nationwide view has to be taken into consideration, referred to as "national." This point of view has to be supplemented by a more local perspective - referred to as "regional"- since initiative and execution are in the hand of local stakeholders. In this study the concept of "region" covers all cities within a circle of approximately $50 \mathrm{~km}$ around Dortmund. In this agglomeration of middle sized cities a strong economic network is applied. Moreover it is the residence of most of Dortmunds employees.

For example, the figures regarding employment give evidence about the fact that the nation-wide economic activities in TPDO create about 16,000 jobs where 11,500 of which are situated in the region which amounts to a share of $70 \%$. The same share applies to the gross value added. A slightly larger percentage of wages and salaries remain in the region.

These figures alone justify the conclusion that in the case of the TDPO public spending was not "throwing tax money into a black hole." On the contrary: every single EURO invested in TPDO yields a profitable return of investment.

The hard facts displayed in this table do not fully describe the success story of TPDO. There are aspects of a more qualitative nature that have to be commented on as well. In order to rank features of this type properly one has to recall the starting point of TPDO amidst the severe crisis of the heavy industry in the 1980's. Then the traditional industries declined and new directions had to be pursued without suitably trained personnel. Employees with higher education background, especially in engineering were desperately sought for.

Nowadays the situation has changed very much to the better. Innovation and the capacity for innovation have been successfully amplified. The following figures demonstrate this potential of companies in TPDO:

- $22 \%$ of their total sales are dedicated to R\&D activities

- $35 \%$ of all firms are filing patents

Table 1. Summary of effects of TechnologieParkDortmund (in $€$, per year, status of 2006)

\begin{tabular}{|c|c|c|c|c|c|}
\hline & & Direct Effects & Indirect Effects & Induced Effects & Total \\
\hline \multirow[t]{2}{*}{ Gross Value Added } & national & \multirow{2}{*}{438 Million } & 335 Million & 132 Million & 905 Million \\
\hline & regional & & 107 Million & 82 Million & 627 Million \\
\hline \multirow[t]{2}{*}{ Employees } & national & \multirow{2}{*}{8,200} & 5,400 & 2,400 & 16,000 \\
\hline & regional & & 1,700 & 1,500 & 11,500 \\
\hline \multirow[t]{2}{*}{ Gross wages and salaries } & national & \multirow{2}{*}{263 Million } & 141 Million & 48 Million & 451 Million \\
\hline & regional & & 44 Million & 30 Million & 337 Million \\
\hline Tax revenue & regional & 20 Million & & & \\
\hline
\end{tabular}




\section{Best Practice of Science / Technology Parks}

\section{WTR 2012;1:276-286}

- $23 \%$ of all firms are engaged in international trade

- $72 \%$ of the employees are graduates of universities.

Establishing the TPDO has resulted in exerting a pull on highly qualified and well trained entrepreneurs and employees. This new appeal doesn't exclusively effect the TPDO or the city of Dortmund. The ambient region on their part has benefited likewise.

In the last decades of the previous century the region was exposed to huge economic challenges. Bold and farsighted actions were needed. Today it is undeniable that the implementation of the TechnologieZentrumDortmund and the TechnologieParkDortmund was one of these big steps forward that deserves the highest compliment.

\section{REFERENCES}

Becker, E., Burger, B., and Hülsmann, Th.(In press). Regional Innovation and Cooperation among Industries, Universities, RD Institutes and Governments, Springer Publisher.

Kleinkes, U.(2004) MST Atlas Germany, Forum Micro Technology at the 2004 Hanover Fair

Gundel, S., and Luttmann, J.(2008) Die regionalwirtschaftlichen Effekte von TechnologieZentrum und TechnologiePark Dortmund, in Materialien zum Siedlungs- und Wohnungswesen, Bd. 42

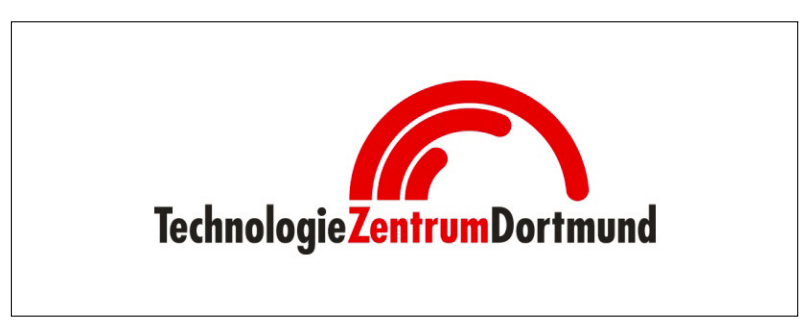

